On the basis of today's information, we believe that the current provisions of the Montreal Protocol can be met, and that an additional step could be adopted to require total phaseout. If this is accomplished, only society as a whole can determine whether any of the aforementioned applications is so critical as to merit exemption from an ultimate phaseout.

\section{Conclusion}

It thus appears that, by building on growing international scientific consensus, policy-makers world-wide are in a position to act cooperatively, not unilaterally, in striving to effect a safe and orderly transition to alternative products.
Unless this transition is carefully planned on an international scale, significant social and commercial disruptions could occur.

DuPont continues to urge a global solution to the CFCozone issue, and remains committed to the Montreal Protocol as the most effective process for addressing the issue. Only a cooperative effort will ensure that the environment is protected for the benefit of future generations.

JoSEPH P. GLAS, Director
'Freon' Products Division
E.I. duPont de Nemours \& Company
Wilmington
Delaware 19898
USA.

\title{
The Mediterranean Blue Plan: Some Further Comments
}

I would like to congratulate this Journal on the publication of Michel Batisse's 'Guest Editorial'-opening this year's Spring issue-on the Mediterranean Blue Plan, which I have read with great interest. The Mediterranean is 'a universe in a nutshell' - a microcosm uniting along its shores societies in all stages of development, of different social and political ideologies, and of diverse cultures and races. To 'manage' the uses of the Mediterranean rationally requires the cooperation of the Economic Commissions of three continents - and yet, in spite of all the problems and difficulties besetting this process, regional cooperation in the Mediterranean seems more advanced than anywhere else (with the possible exception of the Baltic), and is serving as a model for other regions. In a new sense one might say, 'The medium is the message.' The very nature of the medium, the Mediterranean environment, forces nations to harmonize their interests and to cooperate. They can enjoy the Mediterranean together, or they cannot enjoy it at all: a lesson which our political macrocosm should in time learn from this microcosm.

The scenarios so clearly described and analysed by Dr Batisse, therefore, have a significance far transcending the boundaries (wherever these may be!) of the Mediterranean region. But allow me, please, to make a few comments, complementing this expert analysis:

1. Dr Batisse appears to accept uncritically the forecast of a significant, and harmful, increase in the use of fertilizers and pesticides required for increased agricultural production to feed the expanding human populations particularly on the southern and eastern shores of the Mediterranean. Yet such a linear projection might perhaps be misleading, for rapidly-progressing research in genetic manipulation and bioindustrial processes clearly points in the direction of biological rather than chemical systems of fertilization and pesticide over-use: pest-resistant, nitrogen-fixating crops, the sterilization of insects, and other new biotechnologies, may radically alter the environmental impact of agricultural production.

2. A similar argument could be advanced with regard to the environmental impact projection of energy production. This, too, is based on present-day technologies, and does not take sufficient account of the rapid pace of technological development. Dr Batisse does indeed deal with some of the 'alternative' energy sources-particularly solar and wind (tidal possibilities are not applicable in the Mediterranean because of the low tidal ranges); but he does not mention waves, which could be widely utilized for smallscale processes, or OTEC (ocean thermal energy conversion). This last could produce large quantities of energy, in the form of electricity or hydrogen, in the Mediterranean region, considering the depth of the water and the consid- erable temperature differential between the cold bottomwater and the sunlit surface.

True, these technologies are still 'on the drawing board' (although OTEC* has already reached a near-industrial stage). Research and development could be considerably accelerated if they were to be carried out on a regional Mediterranean level, though about this see below.

3. The scenario on transport is somewhat narrow: limited to the environmental impact of the transport of oil and oil products. The Mediterranean transport system ought to be looked at as a whole, including tanker and pipeline transport. And here major changes are in the offing, with the Mediterranean again constituting a model-a pilot project for changes world-wide. If one wanted to decribe these changes with one catch-phrase, this might be "the decolonialization of traffic patterns and the application of the Third Industrial Revolution to shipping and navigation.' Lines of communication (and trade), world-wide, still move largely in the way they did during the age of colonialism: between colonies and their metropolises, or from one colony, via the metropolis, to another colony-not directly between colonies, nor between metropolises of different colonies. This pattern, today, is irrational and wasteful, and wasteful economic systems increase the pressures on the environment.

The ECE† has already initiated a study of traffic flows in the Mediterranean, seeking to redirect them through use of the most advanced electronic and other high technologies. UNCTAD** is initiating a study, complementing and enlarging the ECE study, through a cooperative effort of the three Economic Commissions of Europe, Africa, and Western Asia (ECE, ECA $+\dagger$, ECWA $^{\S}$ ). These studies will have to be taken into consideration for the assessment of the environmental impact of traffic in the Mediterranean.

4. The three 'guidelines', 'recommendations', or 'priorities', at the conclusion of Dr Batisse's Guest Editorial, are all sound and important. They accord well with those of the Report of the World Commission on Environment and Development - the so-called Brundtland Report. ${ }^{B}$ The latter, however, goes further than any other UN document known to us, in pointing to the institutional implications of

\footnotetext{
* OTEC $=$ Ocean Thermal Energy Conversion.

$\dagger \mathrm{ECE}=$ Economic Commission for Europe.

** UNCTAD $=$ United Nations Conference on Trade and Development.

$\dagger \dagger \mathrm{ECA}=$ Economic Commission for Africa

$\S \mathrm{ECWA}=$ Economic Commission for Western Asia.

ø see, for example, Dr Martin W. Holdgate's review occupying page 282 of our Autumn issue of last year. -Ed.
} 
the indivisibility of 'Environment' and 'Development' - or of 'Environment', 'Development', and 'Disarmament'though to emphasize the indivisibility of 'Environment' and 'Development', and to symbolize the integration of 'economics' and 'ecology', a new word ought to be invented-perhaps 'Ecolonomy.'

The 'Brundtland Report' notes that the 'walls' between different Government Departments, traditionally dealing with these sectors separately, are becoming porous: while equally porous are the walls between different levels of governance: national, regional, and global. The Report moreover indicates that new fora of decision-making are needed, where interdisciplinary, transnational problems can be dealt with in their full context of interaction.

The Blue Plan, and Dr Batisse's analysis, do not consider the institutional implications of Mediterranean cooperation. Apart from some minor-and politically and economically insignificant-exceptions, there are no truly 'Mediterranean Institutions.' Yet we now need them!

We have a framework in the Barcelona Convention system and the Mediterranean Action Plan. But the successful implementation of the Action Plan requires that this framework be filled with the establishment of appropriate institutions.

Of these the first might be a Mediterranean Centre for Research and Development in Marine Industrial Technology, as recently proposed by the Government of Malta. This proposal would extend the methodology that was so successfully developed by EUREKA and, in particular, EUROMAR, to the Mediterranean region as a wholeincluding the less-developed countries on its southern shores, which, until now, have been excluded from research and development in high technology. Basically, the organizational pattern would be the same: a coordinating centre housing a conference of ministers. $R \& D^{*}$ projects would be selected to be financed jointly by the private sector, governments, and international institutions, thus sharing risks and reducing costs.

The participation of developing countries in this scheme would be financed by international funding agencies such as the World Bank or the European Investment Bank. This is what is new in the Maltese proposal, and it reflects their desire for a reorientation of the development strategy of 'donor' institutions: a shift towards cooperation in R\&D which is the root and base of scientific-industrial development.

A Mediterranean Centre for Research and Development in Marine Industrial Technology, on the EUREKA-EUROMAR pattern, but covering the whole Mediterranean region and including the 'South', could contribute a great deal towards meeting the challenges and the goals of the Blue Plan, generating environmentally sustainable development and fostering North-South cooperation, and thereby enhancing the chances of peace in the Mediterranean and in the world at large.

\section{Elisabeth Mann Borgese, Chairman Planning Council \\ International Ocean Institute \\ Malta.}

* R\&D = Research \& Development.

\section{This Year's 'Global 500'}

Awards for 'outstanding environmental achievements' were announced recently by the United Nations Environment Programme (UNEP). which made the awards to 94 individuals and organizations in 59 countries. They were named to UNEP's Global 500 role of honour, so-called because it is global in scope and UNEP intends to make a total of 500 such awards by 1991 . This year's laureates, announced on the eve of World Environment Day, 5 June, range from villagers in developing countries to celebrities in the United States and Europe.

The 1988 UNEP award recipients include tree planters in rural Asia, scientists in the Middle East, environmental campaigners in Europe and Latin America, conservation lobbyists in North America, and wildlife experts in Africa. UNEP's Executive Director, Dr Mostafa K. Tolba, an Egyptian microbiologist, said of them: 'These awards celebrate success in protection and improvement of the environment. UNEP hopes the recognition will encourage other individuals and groups to emulate these achievements.' He added: 'The awards honour practical work all over the world in all aspects of the environment which is the resource base for sustainable development everywhere.' There were over 800 nominations from 80 countries for the 1988 UNEP awards.

The UNEP awards programme began last year when 91 environmental achievers from 43 countries were honoured by UNEP. This year, 1988, the laureates include two 'ozone layer' scientists-Professor F. Sherwood Rowland* of the University of California at Irvine, and Dr Joseph C. Farman of the British Antarctic Survey, headquartered at Cambridge, England, UK. Their research contributed to the 1987 international agreement, arranged by UNEP, to limit the use of common chemicals damaging the atmos-

\footnotetext{
* Author of the first paper in this issue.-Ed.
}

pheric ozone layer which protects life on Earth from excessive ultraviolet radiation.

UNEP also honoured a Brazilian tribal leader Davi Yanomani for his ten-years' campaign for protection of tropical forests, and France's Commander Jacques-Yves Cousteau for conservation of marine resources. UNEP awards also went to former US President Jimmy Carter for environmental legislation, British naturalist and filmmaker Gerald Durrell, Dr Perez Olindo who is in charge of Kenya's famous wildlife reserves, Soviet writer Valentin Rasputin who campaigns to protect Siberia's Lake Baikal, and Greenpeace, the international environmental organization.

Awards also went to individuals and groups working to check the spread of deserts and soil erosion in Africa and Asia. Senegal's Foune Traore was honoured for mobilizing village women to protect soil in arid areas of that West African nation. Beyene Abadi, who lives in droughtstricken northern Ethiopia, received a UNEP award for personally planting and tending 1,000 trees around his village of Senafe. And China's Institute for Desert Research was honoured by UNEP for ten years of pioneering work in stabilizing sand-dunes in areas threatened by desertification.

The historic 1987 'debt for nature' swap in Bolivia won an award for the organizers-Conservation International of Washington, DC, and its Bolivian field officer Maria Ortiz. The Bolivian Government has agreed to conserve almost four million acres of forest and grassland in exchange for retirement of part of its foreign debt.

JoHn SHaw, Media Adviser

Office of the Executive Director United Nations Environment Programme P.O. Box 30552

Nairobi, Kenya. 